\title{
Influence of the Number of Rollers on a Tapered Roller
} Bearing

\author{
Alexandre da Silva Scari and Pedro Américo Almeida Magalhães Junior \\ Department of Mechanical Engineering, Pontifical Catholic University of Minas Gerais, Belo Horizonte 30535-901, Brazil
}

Received: April 30, 2014 / Accepted: May 27, 2014 / Published: July 25, 2014.

\begin{abstract}
In roller bearings, the outer ring is usually fixed and the inner ring has the rolling motion. Concerning TRB (tapered roller bearings), this motion generates forces that are transmitted to the outer ring by the tapered rollers. Thus, contact stresses occur and the number of rollers plays a major role with respect to the load distribution. This influence is analyzed in this study by the FEM (finite element method) with commercial code ABAQUS, where two models were evaluated: a common TRB and the same one but with fewer rollers. As an application, a manual automotive transmission was considered for the input loads.
\end{abstract}

Key words: Tapered roller bearings, finite element analysis, automotive manual transmission.

\section{Introduction}

Many factors have great influence in the reaction forces generated in rolling bearings: geometry (curvature, contact angle, clearance, misalignment angle and diameters, etc.), pre-tightening, fluid film lubrification, material properties and so on. All these items have been studied.

Andréason [1] proposed a method to consider the effect of misalignment on the load distribution in tapered roller bearing. Jácome et al. [2] and Yongqi et al. [3] have studied the stress and strain distribution by FEA (finite element analysis) with commercial codes. Rolling contact fatigue and the importance of lubrification have been shown by Ebert [4] and Balcombe et al. [5]. Yamashita et al. [6] have done an analysis of the elastohydrodymanic fluid film thickness in TRB (tapered roller bearings), and Venner et al. [7] showed the film thickness decay in elastohydrodynamically lubricated contacts. Guo and Parker [8] proposed a method to obtain the accurate

Corresponding author: Alexandre da Silva Scari, M.Sc., mechanical engineer, research fields: structural and mechanical analysis, finite elements, elasticity and plasticity, and mechanical behavior of materials. E-mail: alexandrescari@gmail.com. bearing stiffness.

Yet, Chunjun [9] studied an angular contact ball bearing subjected to an axial load by FEA. Also, Harsha [10] proposed an analytical model to for the nonlinear dynamic behavior of a rotating system supported by ball bearings, concerning cage run-out and the number of balls.

It may be seen that just a few studies were carried out concerning the influence of the number of balls (or rollers) in a rolling bearing load distribution. This paper presents an evaluation of this subject, and is organized as follows: Section 2 introduces the literature review; Section 3 shows the methodology concerning the two FE (finite element) models used; Section 4 presents the results and discussions for each FE model; and Section 5 gives conclusions.

\section{Literature Review}

The dynamic load capacity for a roller bearing $(C)$, as the static load, depends on its number of rolling elements. Concerning TRB, the dynamic load capacity is given as follows [11, 12]:

$$
C=f_{c} \cdot\left(i \cdot l_{t} \cdot \cos \alpha_{0}\right)^{\frac{7}{9}} \cdot Z^{\frac{3}{4}} \cdot D_{\max }^{\frac{29}{27}}
$$


where:

- $f_{c}$ : a factor which depends on the roller bearing geometry;

- $i$ : number of rows of rolling elements;

- $l_{t}$ : roller length;

- $\alpha_{0}$ : outer raceway contact angle;

- $\mathrm{Z}$ : number of rolling elements;

- $D_{\max }$ : major tapered roller diameter.

The contact between the tapered roller and the raceways is of the line type, and becomes a semicylindrical form. This leads to a maximum normal stress (Eq. (2)), which depends on the normal force between rolling element and raceway $(Q)$, the roller effective length $(l)$ and the semiwidth of the contact surface $(b) . \quad \sigma_{n}$ must not exceed $4 \mathrm{GPa}$, according to ISO 76 standard [13].

$$
\sigma_{\max }=\frac{2 \cdot Q}{\pi \cdot l \cdot b}
$$

\section{Methodology}

The chosen TRB for this study is identified as 32009 on the manufacturers' catalogs. It is made of SAE 52100 steel and its main geometric characteristics are presented in Fig. 1. Also, it contains 23 tapered rollers and its dynamic load capacity is $58.3 \mathrm{kN}$ [14].

To demonstrate the influence of the number of rollers on a TRB, two FE models were made: the first one concerns the original 32009 TRB (with 23 rollers) and, the second with 18 rollers (5 less). Both FE models were built with linear tetrahedral (cage and tapered rollers) and hexahedral elements (inner and outer rings). The softwares adopted were Hypermesh (pre-processor), Abaqus (solver) and Hyperview (post-processing). It is important to say that a new CAD (computer aided design) model with 18 rollers was built in order to generate the FE model with 5 less rollers. This was necessary in order to guarantee the equal spacing among the tapered rollers and the integrity of the cage.

The boundary conditions are as follows: bearing

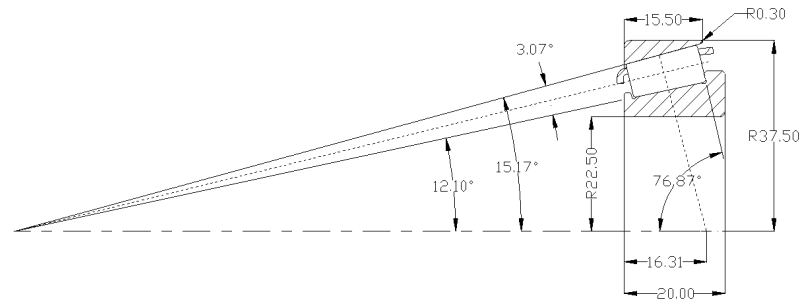

Fig. 132009 TRB geometric characteristics.

outer ring was fixed and a $4.4 \mathrm{kN}$ thrust load was applied in the center of the bearing. Also, there are contact elements between the tapered rollers and the cage, inner and outer raceways. The constraints have penalty functions with scale factor equal to 1 , and the friction value is 0.2 as recommended by NSK [12]. Fig. 2 presents the FE model of the original TRB studied.

The thrust load concerns the maximum torque in 1st gear for a given passenger vehicle, which has $206 \mathrm{~N} \cdot \mathrm{m}$ maximum engine output torque and $277 \mathrm{~mm}$ tire static radius. Knowing the MT gear ratios and dimensions, it may be seen that the maximum thrust load applied on the differential TRB is $4.4 \mathrm{kN}$.

Yet, the dynamic load capacity for the modified TRB was determined analytically, and its new value agrees with the stress results obtained by the FE analysis.

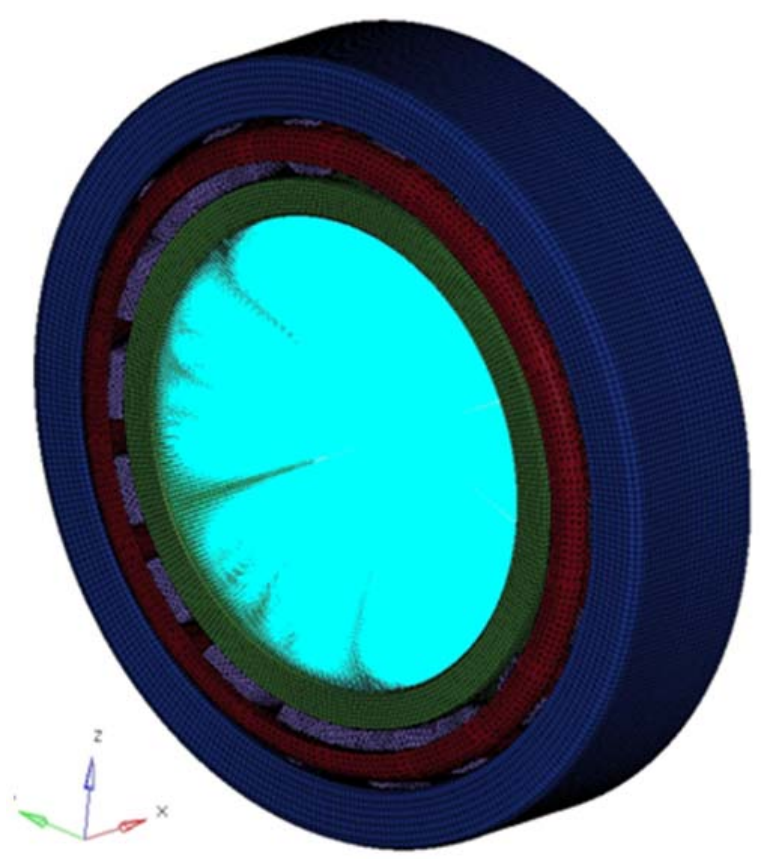

Fig. 2 FE model of the original TRB. 


\section{Results and Discussion}

\subsection{1st FE Model-Original TRB}

For the thrust load considered $(4.4 \mathrm{kN})$, the contact stresses obtained were 3,155 $\mathrm{MPa}$ for the outer raceway (Figs. 3 and 4), and 2,829 $\mathrm{MPa}$ for the tapered roller end (Fig. 5). These results are in accordance with the ISO (International Organization for Standardization) 76 limit ( $<4 \mathrm{GPa})$.

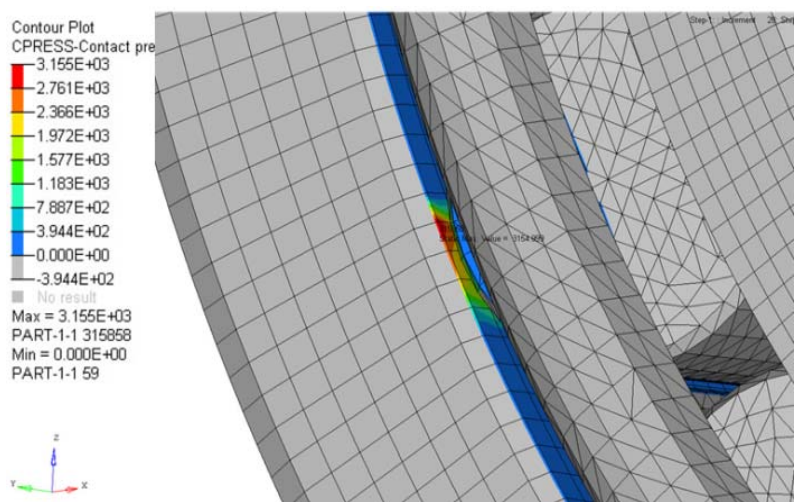

Fig. 3 Contact stress results.

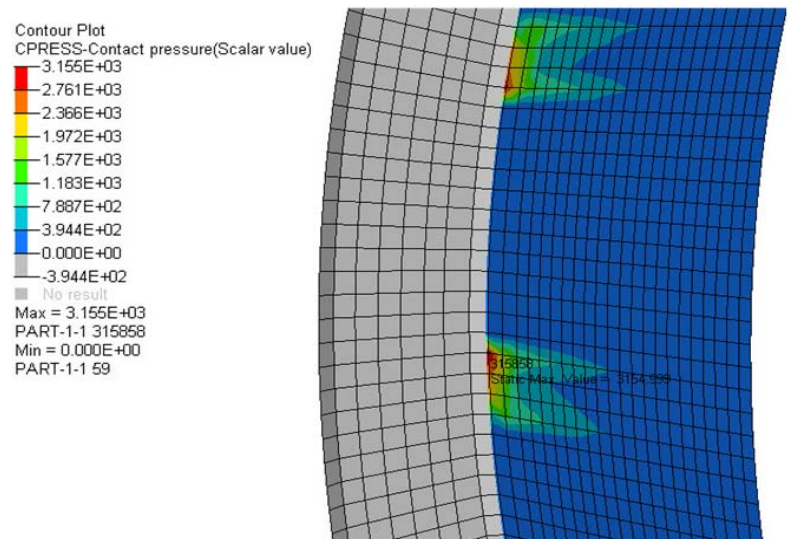

Fig. 4 Contact stress results for the outer raceway.

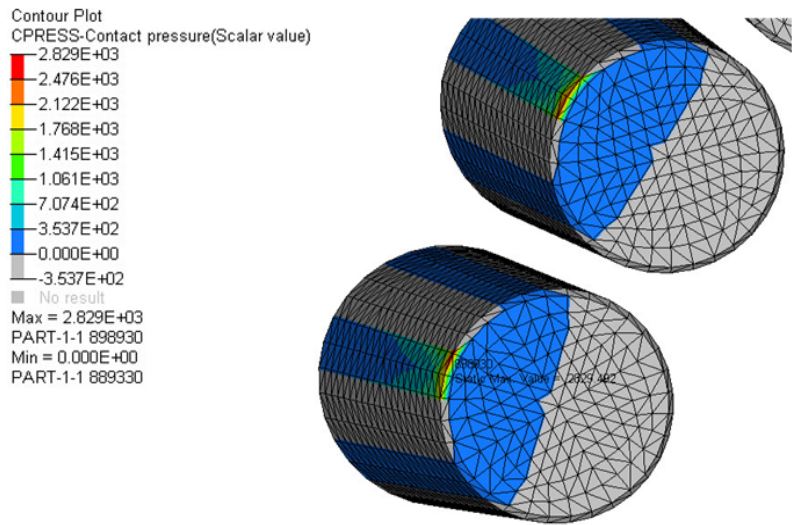

Fig. 5 Contact stress results for the tapered rollers.

\subsection{2nd FE Model-Modified TRB (with 18 Rollers)}

For the thrust load considered $(4.4 \mathrm{kN})$, the contact stresses obtained were 3,391 $\mathrm{MPa}$ for the outer raceway (Fig. 6), and 2,669 MPa for the tapered roller end (Fig. 7). These results are in accordance with the ISO 76 limit (< $4 \mathrm{GPa})$.

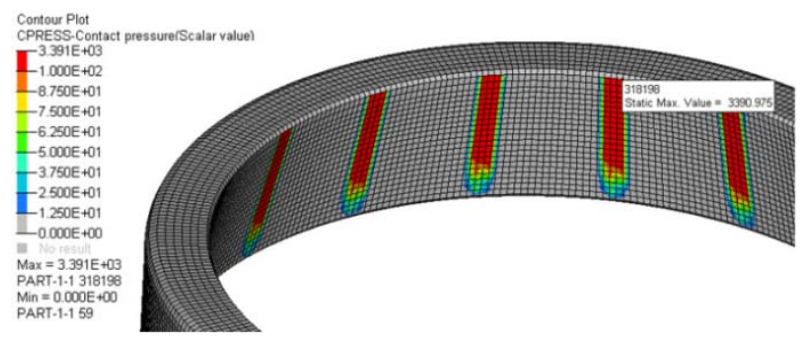

Fig. 6 Contact stress results for the outer raceway.

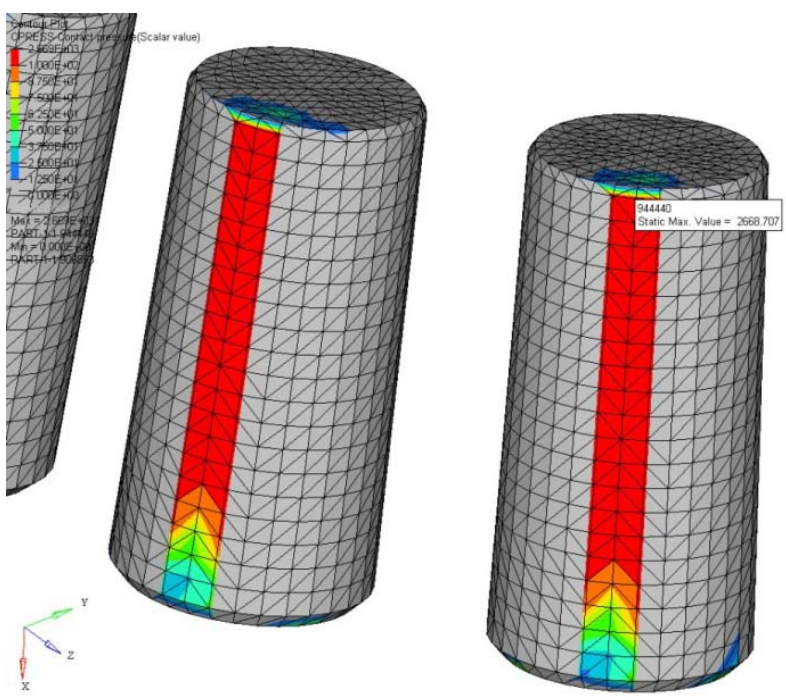

Fig. 7 Contact stress results for the tapered rollers.

Table 1 presents the results summary for both FE models.

Table 1 FEA Results.

\begin{tabular}{llll}
\hline \multirow{2}{*}{ Results (MPa) } & Original & TRB Modified & TRB \\
& & FE Model & FE model \\
\hline Contact & Tapered rollers & 2,829 & 2,669 \\
Stress & Outer raceway & 3,155 & 3,391 \\
\hline
\end{tabular}

The results presented above lead to the following comments:

- All the stress results are in accordance with the ISO 76 limit (< $4 \mathrm{GPa})$;

- The maximum stress results were obtained at the contact between the outer raceway and the tapered roller end. The inner raceway presents the lowest stress values; 
- The cage has low influence in the stress distribution. Its function is to keep the rolling elements equally spaced;

- The lack of 5 rollers (21.7\%) led to a $5.7 \%$ reduction in the tapered roller contact stress, and 7.5\% increase in the outer ring result.

\subsection{Dynamic Load Capacity for the Modified} TRB-Analytical Calculation

Concerning the dynamic load capacity, the only change presented by the modified TRB is the number of tapered rollers (from 23 to 18). Thus, in Eq. (1), the $C_{\text {modified }}$ can be obtained as follows:

$$
C_{\text {modified }}=C \cdot \frac{\mathrm{Z}_{\text {modified }}^{3 / 4}}{Z^{3 / 4}}
$$

With $C=58.3 \mathrm{kN}, z=23$ and $z_{\text {modified }}=18$, it may be seen that $C_{\text {modified }}=48.5 \mathrm{kN}$. Table 2 presents a comparison between the dynamic load capacities written previously.

Table 2 Comparison between the dynamic load capacities.

\begin{tabular}{llll}
\hline Bearing & $\begin{array}{l}\text { Original } \\
\text { TRB }\end{array}$ & $\begin{array}{l}\text { Modified } \\
\text { TRB }\end{array}$ & $\Delta(\%)$ \\
\hline $\begin{array}{l}\text { Dynamic load } \\
\text { capacity }(C)\end{array}$ & $58.3 \mathrm{kN}$ & $48.5 \mathrm{kN}$ & $-16.8 \%$ \\
\hline
\end{tabular}

In Table 2, the dynamic load capacity decreased (16.8\%), according with the higher contact stress obtained by the outer raceway. Although this change seems pejorative, it does not means that the modified TRB cannot work. For example, the chosen passenger vehicle has the original TRB applied on the differential of the manual transmission. If it would be changed to the modified TRB, the new bearing life ( $\left.L_{10 \mathrm{~h}}\right)$ would be $979.9 \%$ greater than the minimum required [15].

\section{Conclusions}

The goal of this study was to evaluate the influence of the number of rolling elements in a tapered roller bearing by FEA. Two FE models were considered: the original (with 23 rollers) and the modified (with 18 rollers).
The contact stress is more relevant between the tapered roller and the outer raceway, as expected. Yet, the outer raceway presents the highest contact stress.

For a given bearing, the lack of some tapered rollers increases the contact stress in the outer ring and reduces in the remaining rollers. Although this reduces the dynamic load capacity and the total bearing life $\left(L_{10 \mathrm{~h}}\right)$, the power loss is also lower due to less friction between the rollers and the raceways. Concerning passenger vehicles, less friction in this case may be associated to less fuel consumption.

\section{Acknowledgments}

The authors would like to thank the support of PUC Minas (Pontificia Universidade Catolica de Minas Gerais), CAPES (Coordenação de Aperfeiçoamento de Pessoal de Nível Superior), CNPq (Conselho Nacional de Desenvolvimento Científico e Tecnológico) and the FAPEMIG (Fundação de Amparo a Pesquisa de Minas Gerais).

\section{References}

[1] Andréason, S. 1973. "Load Distribution in a Taper Roller Bearing Arrangement Considering Misalignment.” Tribology International 6 (3): 84-92.

[2] Jácome, E. L., Alonso, J. M., and López, V. D. 2010. “A Study of Sliding between Rollers and Races in a Roller Bearing with a Numerical Model for Mechanical Event Simulations.” Tribology International 43: 2175-82.

[3] Yongqi, Z., Qingchang, T., Kuo, Z., and Jiangang, L. 2012. "Analysis of Stress and Strain of the Rolling Bearing by FEA Method.” Physics Procedia 24: 19-24.

[4] Ebert, F. J. 2010. "Fundamentals of Design and Technology of Rolling Element Bearings.” Chinese Journal of Aeronautics 23: 123-36.

[5] Balcombe, R., Fowell, M. T., Olver, A. V., Ioannides, S., and Dini, D. A. 2011, "Coupled Approach for Rolling Contact Fatigue Cracks in the Hydrodynamic Lubrication Regime: The Importance of Fluid/Solid Interactions.” Wear 271: 720-33.

[6] Yamashita, R., Dowson, D., and Taylor, C. M. 1997. “An Analysis of Elastohydrodynamic Film Thickness in Tapered Roller Bearings.” Elsevier Science B. V. 32: 617-37.

[7] Venner, C. H., Zoelen, M. T., and Lugt, P. M. 1012. “Thin Layer Flow and Film Decay Modeling for Grease 
Lubricated Rolling Bearings.” Tribology International 47: 175-87.

[8] Guo, Y., and Parker, R. G. 2012. "Stiffness Matrix Calculation of Rolling Element Bearings Using a Finite Element/Contact Mechanics Model.” Mechanism and Machine Theory 51: 32-45.

[9] Chunjun, P. 2009. "Static Analysis of Rolling Bearings Using Finite Element Method.” M.Sc. thesis, Universität Stuttgart.

[10] Harsha, S. P. 2006. "Nonlinear Dynamic Analysis of Rolling Element Bearings due to Cage Run-Out and Number of Balls.” Journal of Sound and Vibration 289:
360-81.

[11] Pope, J. E. 1997. Rules of Thumb for Mechanical Engineers. Texas: Gulf Publishing.

[12] NSK. Technical Report, 1992. Catalog n. E728f. Japan.

[13] International Organization for Standardization. 2006. ISO 76: Rolling Bearings-Static Load Ratings.

[14] SKF. General Catalog, 2009.

[15] Scari, A. S. 2012. "Static Analysis of Tapered Roller Bearings Applied in Automotive Manual Transmissions." M.Sc. thesis, Pontifical Catholic University of Minas Gerais. 